\title{
Transcriptional Regulation and Signaling of Developmental Programmed Cell Death in Plants
}

\author{
Cheng Jiang ${ }^{1}$, Jiawei Wang ${ }^{1}$, Hua-Ni Leng ${ }^{2}$, Xiaqin Wang ${ }^{1}$, Yijing Liu' ${ }^{1}$, Haiwen Lu', \\ Meng-Zhu Lu' ${ }^{1}$ and Jin Zhang ${ }^{1 *}$
}

'State Key Laboratory of Subtropical Silviculture, College of Forestry and Biotechnology, Zhejiang A\&F University, Hangzhou, China, ${ }^{2}$ Department of Horticultural Science, North Carolina State University, Raleigh, NC, United States

Developmental programmed cell death (dPCD) has multiple functions in plant growth and development, and is of great value for industrial production. Among them, wood formed by xylem dPCD is one of the most widely used natural materials. Therefore, it is crucial to explore the molecular mechanism of plant dPCD. The dPCD process is tightly regulated by genetic networks and is involved in the transduction of signaling molecules. Several key regulators have been identified in diverse organisms and individual PCD events. However, complex molecular networks controlling plant dPCD remain highly elusive, and the original triggers of this process are still unknown. This

Edited by:

Elizabeth P. B. Fontes,

Universidade Federal de Viçosa, Brazil

Reviewed by:

Ting Zhao,

Zhejiang University, China

Yunjun Zhao,

Brookhaven National Laboratory

(DOE), United States

${ }^{*}$ Correspondence:

Jin Zhang

zhangj@zafu.edu.cn

orcid.org/0000-0002-8397-5078

Specialty section:

This article was submitted to

Plant Biotechnology,

a section of the journal

Frontiers in Plant Science

Received: 30 April 2021

Accepted: 02 July 2021

Published: 29 July 2021

Citation:

Jiang C, Wang J, Leng H-N, Wang X, Liu Y, Lu H, Lu M-Z and

Zhang J (2021) Transcriptional

Regulation and Signaling

of Developmental Programmed Cell

Death in Plants.

Front. Plant Sci. 12:702928.

doi: 10.3389/fp/s.2021.702928 review summarizes the recent progress on the transcriptional regulation and signaling of dPCD during vegetative and reproductive development. It is hoped that this review will provide an overall view of the molecular regulation of $\mathrm{APCD}$ in different developmental processes in plants and identify specific mechanisms for regulating these dPCD events. In addition, the application of plants in industrial production can be improved by manipulating $\mathrm{dPCD}$ in specific processes, such as xylogenesis.

Keywords: programmed cell death, signaling, transcriptional regulation, plant development, cell differentiation

\section{INTRODUCTION}

Programmed cell death (PCD) is considered a behavior of self-salvage that is genetically controlled to eliminate no longer needed and damaged cells selectively or to differentiate specific cell types for efficient utilization of nutrition, reproduction, and other aspects (Daneva et al., 2016). In plants, PCD can be classified into developmentally induced PCD ( $\mathrm{dPCD}$, triggered as the ultimate step of cell-type specific differentiation programs) and environmentally induced PCD (ePCD, triggered by diverse abiotic stresses) according to the way it is triggered (Petrov et al., 2015; Huysmans et al., 2017). In an early work, PCD and autolysis were considered to be interchangeable or distinct in various studies. However, in some cases of developmental cell death, PCD and autolysis can easily be distinguished as two different biological processes with unique biochemical mechanisms and functional purposes (Escamez and Tuominen, 2014). dPCD occurs during vegetative and reproductive development and is the final differentiation process in specific cell types, such as xylem, root cap cells, trichomes, and anther tapetum (Olvera-Carrillo et al., 2015).

Over the last two decades, numerous studies unscrambling dPCD have focused on (1) the extracellular and intracellular signals that initiate $\mathrm{APCD}$ or are altered during $\mathrm{dPCD}$ (Gechev and Hille, 2005), (2) the transcriptional regulation of specific gene expression to control dPCD (CubríaRadío and Nowack, 2019), and (3) hydrolytic enzymes such as proteases and nucleases, which 
are key executors of dPCD (Buono et al., 2019). The aim of this review is to shed light on the most common instances of $\mathrm{APCD}$ in plant development, focusing on the molecular regulation of the dPCD process, to discuss future research directions contributing to a clear understanding of the mechanisms of dPCD and to take full advantage of dPCD in plants to improve the efficiency of production.

\section{TRANSCRIPTIONAL REGULATION OF dPCD}

\section{Transcriptional Regulation of Reproductive dPCD}

Reproductive growth is a critical process for plant population survival and genetic diversity. Recently, Wang et al. (2021) summarized the regulatory framework of flower-specific dPCD such as tapetal degeneration, pollen tube rupture, transmitting tract formation, and self-incompatibility. Here, we focus on the transcriptional regulation of $\mathrm{dPCD}$ in male and female germ cell formation, and fertilization and seed development.

\section{Male Germ Cell Formation}

Dehiscence of the anther and release of pollen rely on the PCD of the tapetum, and the precise timing of its degeneration is crucial for pollen maturation (Gómez et al., 2015). The transcriptional regulation mechanism that controls $\mathrm{dPCD}$ during tapetum differentiation has been reported. A group of basic helix-loop-helix (bHLH) transcription factors (TFs) can positively regulate tapetal PCD. bHLH142 acts downstream of the bHLH TF UNDEVELOPED TAPETUM1 (OsUDT1) and regulates the bHLH TF ETERNAL TAPETUM1 (OsEAT1) to induce tapetal PCD. Furthermore, two genes (AP25 and AP37) that encode aspartic proteases for tapetal PCD are under the regulation of OsEAT1 (Ko et al., 2014). In rice, TAPETUM DEGENERATION RETARDATION (OsTDR) activates a cysteine protease-encoding gene $(O s C P 1)$ to induce tapetal PCD, and its activation is repressed by an aldehyde dehydrogenase (OsALDH) (Xie et al., 2020). TDR INTERACTING PROTEIN2 (OsTIP2) can interact with and directly regulate the expression of OsTDR and OsEAT1 (Fu et al., 2014). PERSISTENT TAPETAL CELL encoding genes (OsPTC1 and OsPTC2) were proved to regulate the expression of OsEAT1, OsAP1, and OsAP25 (Uzair et al., 2020). Arabidopsis AtMYB80 might suppress tapetal PCD by influencing the expression of the papain-like cysteine protease gene AtCEP1, but the precise regulation mechanism is still unclear (Zhang et al., 2014). In addition, AtMYB80 might activate the PCD-inhibiting aspartic protease UNDEAD, and a mutation in AtMYB80 caused precocious tapetum degeneration in Arabidopsis (Phan et al., 2011). These results show that a regulatory network is crucial for the precise timing of tapetal PCD and male fertility (Figure 1).

\section{Female Germ Cell Formation}

Female gametophytes develop inside the ovules, which originate from a meiotic product. One functional megaspore survives, and three megaspores degenerate. During these processes, the expression of Arabinogalactan protein 18 (AtAGP18) is needed in the abaxial pole of the ovule to ensure the survival of functional megaspores (Demesa-Arévalo and Vielle-Calzada, 2013). The nucellus is an ephemeral tissue whose degeneration is controlled by female gametophytes (Chen et al., 2014). The TF OsMADS29 can regulate the expression of the cysteine protease gene $(C E P)$, thereby promoting nucellar degeneration in rice (Yin and Xue, 2012). Another PCD-related CEP gene, a vacuolar processing enzyme ( $H v V P E)$, was shown to be upregulated during nucellar cell death in barley (Radchuk et al., 2011).

\section{Fertilization and Seed Development}

During fertilization, several cells are tightly controlled for elimination. Pollen tubes growth toward the ovule is guided by the transmitting tract, the death of which is considered to be important. Cell death of the transmitting tract to make way for growing pollen tubes is regulated by two bHLH TFs (AtSTY and $A t H E C)$ and two auxin response factor (ARF) genes (AtARF6 and AtARF8) (Kaminaka et al., 2006). Once pollen tubes arrive at ovules, synergids undergo cell death, and three synergidexpressed genes, FERONIA (AtFER), LORELEI (AtLRE), and NORTIA (AtNTA), are required (Kessler and Grossniklaus, 2011). AtMYB97, AtMYB101, and AtMYB120 positively regulate receptive synergid degeneration after the proper discharge of sperm cells (Liang et al., 2013). ZHOUPI (AtZOU/AtRGE1) and INDUCER OF CBP EXPRESSION 1 (AtICE1) promote the breakdown of the embryo-surrounding region, and lossof-function mutants of these genes lead to misshaped embryos (Denay et al., 2014).

\section{Transcriptional Regulation of Vegetative dPCD Xylogenesis}

Secondary xylem is the most abundant biomass produced by plants and concurrently functions in structural and mechanical support and transport tissues distributing water and solutes. Xylogenesis consists of xylem generation, differentiation, and PCD processes (Escamez and Tuominen, 2014). In this process, a typical dPCD event is the formation of the tracheal element (TE), which loses its contents and forms a functional region composed of hollow, dead tubes. VASCULAR NAC DOMAIN (VNDs) and NAC SECONDARY WALL THICKENING PROMOTING FACTOR (NSTs) are known to function as key regulators of TE secondary cell wall (SCW) formation and cell death (Zhang et al., 2018a). These NAC TFs are regarded as first layer regulators in the progression of the SCW regulatory network, subsequently regulating the second layer master switches MYB46 and MYB83 (Zhong et al., 2007). VNDs also regulate the expression of TE differentiation inhibitors, such as SUPPRESSOR OF ACAULIS 51 (SAC51) and XYLEM NAC DOMAIN 1 (XND1) (Zhong et al., 2010). Moreover, hydrolytic enzymes downstream of VNDs, such as xylem cysteine proteinase (AtXCP1 and AtXCP2) and metacaspase9 (AtMC9), are the executors of autolysis during dPCD.

\section{Root Cap}

The root cap ensheathes the root and has important functions for root growth, gravity sensing, root system architecture, and 


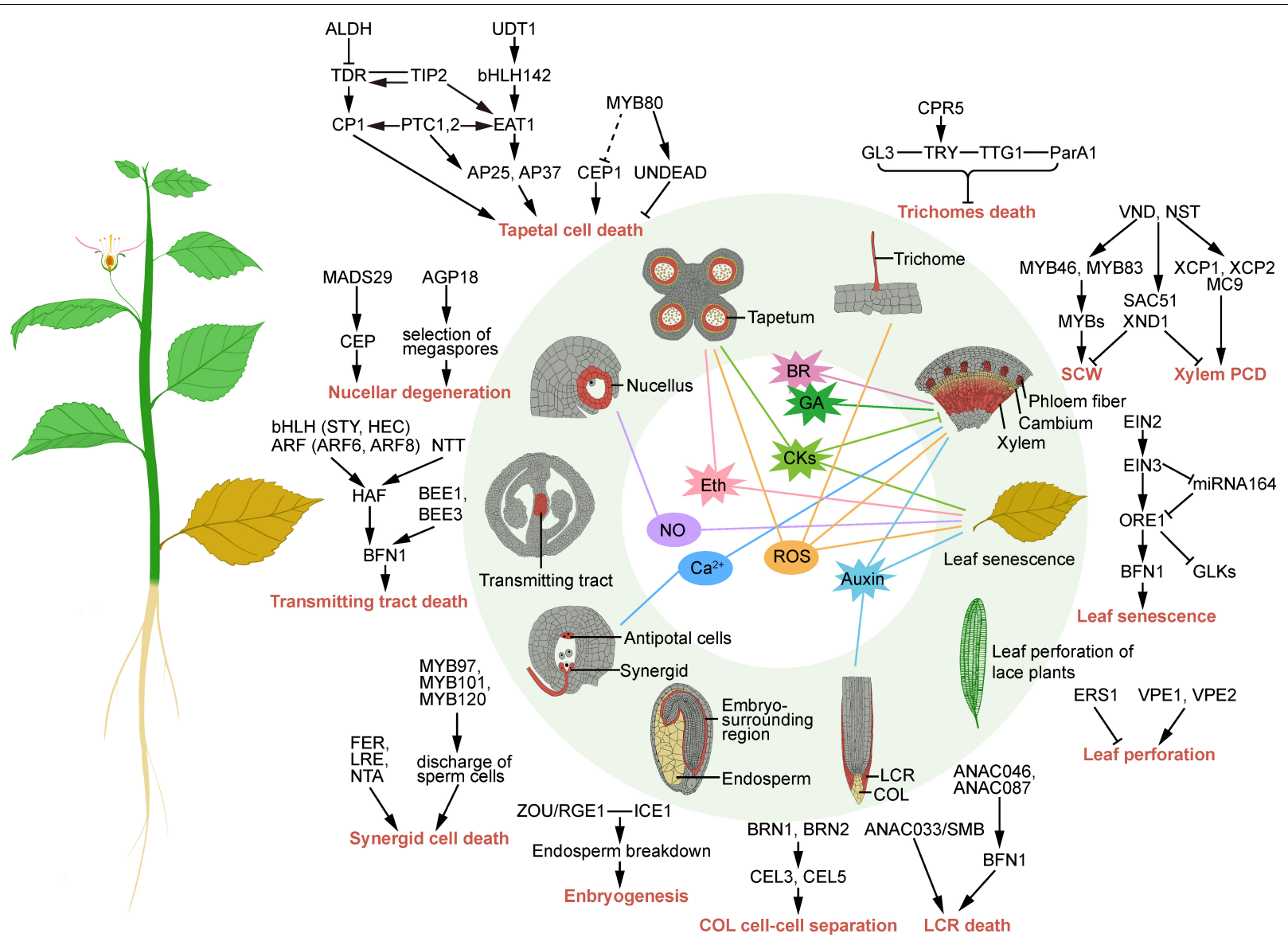

FIGURE 1 | Schematic representation of the transcriptional regulation and signaling of developmental programmed cell death in plants. Arrows and a "T" at the ends of lines represent transcriptional activation and repression, respectively. Lines without arrows or a "T" represent protein-protein interactions; dotted line represents unclear regulation.

protection of the stem cells in the root tip (Kumpf and Nowack, 2015). The root cap has to maintain its size and position at the root tip by sloughing old cells and producing new cells; the disposal of old cells is a PCD process. In Arabidopsis, the root cap can be distinguished into two tissue types, the central columella root cap (COL) and the peripheral lateral root cap (LRC). Two NACs, BEARSKIN1 (AtBRN1) and AtBRN2, regulate root cap-expressed CELLULASE3 (AtCEL3) and AtCEL5, and control cell-cell separation in mature COL layers (Bennett et al., 2010). The TF ANAC033/SOMBRERO was shown to transcriptionally control LRC differentiation and preparation for cell death (Fendrych et al., 2014). In addition, two other NACs (AtANAC087 and AtANAC046) are sufficient to activate the expression of cell death-associated genes and induce $\mathrm{APCD}$ via the nuclease BIFUNCTIONAL NUCLEASE1 (AtBFN1) (Huysmans et al., 2018).

\section{Leaf Morphogenesis}

The production of various leaf shapes during leaf morphogenesis is also regulated by $\mathrm{dPCD}$. Leaf perforation exists in lace plants, and few aroids are caused by PCD (Gunawardena, 2008). The transcription level of the ethylene receptor gene AmERS1a was significantly reduced in leaves undergoing PCD, indicating that ethylene plays an important role in $\mathrm{APCD}$ during lace plant perforation (Rantong et al., 2015). Two VPE genes (AmVPE1 and AmVPE2) were identified with high expression levels in the preperforation developmental stage and late window stage of lace plants, respectively (Rantong and Gunawardena, 2018). However, the detailed transcriptional regulation mechanism is still unclear.

\section{Leaf Senescence}

The last stage of leaf senescence is a PCD process influenced by numerous internal and external environmental signals, which are controlled by a very complex gene regulatory network (Woo et al., 2019). Ethylene controls the leaf senescence PCD by the trifurcate pathway. ETHYLENE-INSENSITIVE2 (AtEIN2) perceiving ethylene activates the expression of AtEIN3, which represses miR164 (Li et al., 2013). MiR164 subsequently suppresses the expression of ORESARA1/ANAC092 (AtORE1), which directly contributes to controlling AtBFN1 (Matallana-Ramirez et al., 2013), and inhibits the activity of the chloroplast-supporting TFs GOLDEN-LIKE1 (AtGLK1) and AtGLK2 (Rauf et al., 2013). 


\section{Trichome Differentiation}

Trichomes are epidermal outgrowths that play various protective roles and provide valuable resources for plant development. Trichome cells were proved to die finally with chromatin condensation, nuclear fragmentation, and endoplasmic reticulum dilation (Papini et al., 2010). Trichome death is also regulated by CONSTITUTIVE PATHOGEN RESPONSE5 (AtCPR5) through linking endoreduplication and cell division (Kirik et al., 2001), and the effects of the cpr5 mutant were epistatic to those of trichome developmental regulators TRIPTYCHON (AtTRY) and GLABRA3 (AtGL3) (Brininstool et al., 2008). In Nicotiana, silencing TRANSPARENT TESTA GLABRA1 (NtTTG1) in trichomes resulted in the elimination of hypersensitive cell death induced by ParA1 (Wang et al., 2009).

\section{SIGNALS CONTROLLING DEVELOPMENTAL PCD}

\section{Plant Hormones}

Auxin was reported to be involved in xylem formation, root cap morphogenesis, and leaf senescence. Dying cells were shown to facilitate the production of indole-3-acetic acid (IAA), as their proteins were hydrolyzed and some of the tryptophan was released to adjacent cells (Sheldrake, 2021). The auxin dynamics among dying cells and adjacent cells play a crucial role in plant growth and development through PCD. The levels of auxin immediately increase around differentiating xylem cells in leaf veins, petals, and roots when they are dying (Brunoud et al., 2012). When polar auxin transport is inhibited, xylem differentiation is further induced locally, along with high levels of auxin (Ravichandran et al., 2020). In this process, differentiating xylem cells were considered "stem-cell organizers" leading to the formation of a new organizer adjacent to cambial stem cells and differentiation into mature xylem themselves. In the lateral root cap, PCD and auxin form a cyclic action that regulates the periodicity of lateral organ induction, coordinating primary root growth with root branching (Xuan et al., 2016). Furthermore, in senescent leaves, tryptophan and auxin levels increase dramatically, which accelerates leaf senescence (Araújo et al., 2011). These studies indicate that auxin acts as an important signal involved in cell differentiation, especially in developmentally controlled cell death. Furthermore, it mainly appears to initiate these processes (Vanneste and Friml, 2009).

Cytokinin plays a central role in cell division and differentiation through an antagonistic interaction with auxin. Cytokinin can also affect the dPCD of xylem, leaves during senescence, and tapetum. In Arabidopsis, the cell fate to protoxylem exhibits high auxin and low cytokinin signaling, while the cell fate to procambium exhibits high cytokinin but low auxin signaling in roots (Bishopp et al., 2011). In a loss-of-function mutant of the cytokinin receptor AtAHK3, leaf senescence was delayed with reduced sensitivity to cytokinin (Kim et al., 2006). Through expression analysis of phytohormone biosynthesis and signaling genes, cytokinin is needed during earlier stages of rice tapetum and not needed at the uninuclear microspore stage (Hirano et al., 2008). Therefore, regulating cytokinin at low levels ensures well-organized PCD in plants. It has also been demonstrated that high levels of cytokinin call induce PCD in root cortex cells of Vicia faba ssp. minor seedlings (Kunikowska et al., 2013) and in cultured Arabidopsis cells (Vescovi et al., 2012).

Ethylene is widely known as the plant hormone responsible for a number of developmental processes. Tapetal cell death and leaf senescence require ethylene. The reduction of ethylene production and signal transduction leads to delayed leaf senescence (Graaff et al., 2006). Some plants form aerenchyma in response to a hypoxic environment; however, blocking the ethylene receptor that makes the cells insensitive to ethylene can avoid PCD to allow aerenchyma to form (Liu et al., 2019). Ethylene signaling is needed for the induction of PCD in epidermal cells of deepwater rice (Steffens and Sauter, 2005). The expression and activation of signaling genes involved in ethylene specifically occurred in tapetal cells concurrently, which regulated tapetal cell death (Hirano et al., 2008). In addition, ethylene is also an active signal in floral organ formation and development (Wang et al., 2010).

Moreover, several other phytohormones are also involved in dPCD-related processes, e.g., gibberellin is essential in vascular differentiation (Eriksson et al., 2000), brassinosteroids initiate TE differentiation (Milhinhos and Miguel, 2013), salicylic acid is associated with hypersensitive reaction and has dual functions in cell death control (Radojičić et al., 2018), and jasmonic acid is necessary for leaf senescence (He et al., 2002). In summary, phytohormones play many roles in plant dPCD. However, the molecular and biochemical mechanisms of plant hormones as signals for the dPCD of different tissues and organs remain to be elucidated (Figure 1).

\section{Reactive Oxygen Species}

Continuously generated reactive oxygen species (ROS), such as singlet oxygen $\left({ }^{1} \mathrm{O}_{2}\right)$, superoxide $\left(\mathrm{O}_{2}{ }^{-}\right)$, hydrogen peroxide $\left(\mathrm{H}_{2} \mathrm{O}_{2}\right)$, and hydroxyl radical $(\mathrm{HO})$, act as signaling molecules that coordinate various plant processes, namely, tapetal cell death, trichome death, xylogenesis, and leaf senescence (Gechev et al., 2006). ROS are regarded not only as signals but also as byproducts of aerobic pathways generated in different cellular compartments and cause PCD at higher concentrations (Gechev and Hille, 2005). MAPKs involved in relaying the $\mathrm{H}_{2} \mathrm{O}_{2}$ signal mediate PCD triggered by chloroplast-generated $\mathrm{H}_{2} \mathrm{O}_{2}$ (Liu et al., 2007). The chloroplast protein EXECUTER1, acting together with EXECUTER2, could transfer oxidative signals from the plastid to the nucleus, leading to cell death (Lee et al., 2007). The $\mathrm{H}_{2} \mathrm{O}_{2}$ signal transmitted to ROS-specific TFs could lead to $\mathrm{H}_{2} \mathrm{O}_{2}$ dependent cell death (Gadjev et al., 2006). In the rice mads3 mutant, anthers exhibit oxidative stress-related phenotypes, since tapetal PCD occurs prematurely (Hu et al., 2011). ROS production by NADPH oxidases also acts on tapetal PCD progression (Xie et al., 2014). Elimination of $\mathrm{H}_{2} \mathrm{O}_{2}$ through nonenzymatic and enzymatic pathways maintains the level of ROS, while catalase, peroxidase, ascorbate peroxidase, and glutathione reductase are considered to be the main $\mathrm{H}_{2} \mathrm{O}_{2}$ scavengers, which can effectively reduce the amount of $\mathrm{H}_{2} \mathrm{O}_{2}$ (Kapoor et al., 2015). In summary, the role of ROS in the dPCD process strictly depends 
on its concentration, and its interaction with other signaling molecules also determines cell fate (Niu and Liao, 2016).

\section{Nitric Oxide}

Nitric oxide (NO) is a small gaseous and highly reactive molecule that can take part in a wide range of physiological processes, such as nucellar degeneration and leaf senescence. Due to NO being highly reactive, a series of NO derivatives could be formed, resulting in a redox-mediated modification in plants. The effects of $\mathrm{NO}$ as an activator or repressor seem to be due to the concentration and timing patterns of NO (Mur et al., 2012). High levels of NO are associated with the progression of natural senescence, cell death, and DNA fragmentation (Carimi et al., 2005). Studies have indicated that $\mathrm{NO}$ and $\mathrm{H}_{2} \mathrm{O}_{2}$ can be induced to synthesize each other and that the signaling crosstalk between $\mathrm{H}_{2} \mathrm{O}_{2}$ and $\mathrm{NO}$ synergistically regulates leaf cell death and delays senescence (Iakimova and Woltering, 2015). During nucellar cell degeneration, considerable production of $\mathrm{NO}$ and $\mathrm{H}_{2} \mathrm{O}_{2}$ caused an induction of caspase-like proteases, leading to nucellar dPCD (Lombardi et al., 2010). In addition, rapid and transient increases in ROS and NO were also detected by self-incompatibility in the pollen tube growth of Papaver (Wilkins et al., 2011).

\section{Calcium}

$\mathrm{Ca}^{2+}$ is a core signaling molecule in plants that is involved in many physiological processes, such as PCD of synergids and xylogenesis (Uslu and Grossmann, 2016). The change in intracellular $\mathrm{Ca}^{2+}$ concentration plays an important role in signaling transmission during a series of cellular processes (Kong et al., 2015). The $\mathrm{Ca}^{2+}$ increase in the cytosol was verified to be an early signal that occurred upstream of the vacuolar breakdown in self-incompatibility (Wilkins et al., 2015). Calcium-mediated signaling between two synergids determined their fate (death or survival) in the control of sperm delivery (Ngo et al., 2014). In xylogenic Zinnia cultures, $\mathrm{Ca}^{2+}$ influx into the cell was required for cell death and implicated as a trigger after SCW deposition (Groover and Jones, 1999). $\mathrm{Ca}^{2+}$ influx has been demonstrated to be mediated by $\mathrm{H}_{2} \mathrm{O}_{2}$ signaling in the plasma membrane of root cells, resulting in root elongation (Han et al., 2014). Because of various types of $\mathrm{Ca}^{2+}$ receptors and channels, $\mathrm{Ca}^{2+}$ signaling can be delivered widely. For example, $\mathrm{Ca}^{2+}$-dependent DNases (CaN) participate in the PCD of secretory cavity cells through nuclear DNA degradation in Citrus (Bai et al., 2020). In Eucommia ulmoides, EuCaN1, and EuCaN2 were identified to be involved in secondary xylem development (Chen et al., 2012).

\section{REFERENCES}

Araújo, W. L., Ishizaki, K., Nunes-Nesi, A., Tohge, T., Larson, T. R., Krahnert, I., et al. (2011). Analysis of a range of catabolic mutants provides evidence that phytanoyl-coenzyme a does not act as a substrate of the electrontransfer flavoprotein/electron-transfer flavoprotein:ubiquinone oxidoreductase complex in Arabidopsis during dark-induced senes. Plant Physiol. 157, 55-69. doi: 10.1104/pp.111.182188

Bai, M., Liang, M., Huai, B., Gao, H., Tong, P., Shen, R., et al. (2020). Ca ${ }^{2+}$ dependent nuclease is involved in DNA degradation during the formation of the

\section{CONCLUSION AND FUTURE PERSPECTIVES}

Current studies have shown that the fate of cells undergoing PCD is controlled by complex signaling and transcriptional regulatory networks. Transcriptional regulation has been revealed to play a key role in specific dPCD events. However, the link between signaling pathways and $\mathrm{dPCD}$-related gene expression regulation is rarely clearly established. Especially in woody plants, the signal transduction and transcriptional regulatory mechanism of dPCD during wood formation are still unclear. Recently, Zhang et al. (2018b) used a combination of expression quantitative trait loci (eQTL) analysis and genome-wide association study (GWAS) to successfully identify crucial genes that control metabolite synthesis and further upstream transcription factors. This approach provides a new strategy for exploring new regulatory mechanisms in biological processes. Therefore, combining cell biology, biochemistry, and molecular biology methods to detect how signaling pathways control dPCD through gene regulatory networks will become an overall trend in future research. Specifically, xylogenesis contributes to the largest bioenergy source, in which the components and contents of SCW are the main influencing factors in the improvement of industrial production. In short, the analysis of the molecular regulation mechanism of plant dPCD can lay the foundation for regulating specific developmental processes of plants through genetic engineering methods and further applying their products to industrial production.

\section{AUTHOR CONTRIBUTIONS}

JZ conceived the study. CJ and JZ collected and synthesized the data and draft the manuscript. JW, H-NL, XW, YL, HL, and $\mathrm{M}-\mathrm{ZL}$ revised the manuscript. All authors contributed to the article and approved the submitted version.

\section{FUNDING}

This study was supported by the National Natural Science Foundation of China (32001285) to CJ, the National Key R\&D Program "International Cooperation in Science and Technology Innovation between Governments" (2019YFE0119100) to M-ZL, and the Zhejiang A\&F University Research and Development Fund Talent Startup Project (2021LFR013) to JZ.

secretory cavity by programmed cell death in fruit of Citrus grandis 'Tomentosa'. J. Exp. Bot. 71, 4812-4827. doi: 10.1093/jxb/eraa199

Bennett, T., Toorn, A. V. D., Sanchez-Perez, G. F., Campilho, A., Willemsen, V., Snel, B., et al. (2010). SOMBRERO, BEARSKIN1, and BEARSKIN2 regulate root cap maturation in Arabidopsis. Plant Cell 22, 640-54. doi: 10.1105/tpc. 109.072272

Bishopp, A., Help, H., El-Showk, S., Weijers, D., Scheres, B., Friml, J., et al. (2011). A mutually inhibitory interaction between auxin and cytokinin specifies vascular pattern in roots. Curr. Biol. 21, 917-926. doi: 10.1016/j.cub.2011.04. 017 
Brininstool, G., Kasili, R., Simmons, L. A., Kirik, V., Hülskamp, M., and Larkin, J. C. (2008). Constitutive expressor of Pathogenesis-Related Genes5 affects cell wall biogenesis and trichome development. BMC Plant Biol. 8:58. doi: 10.1186/ 1471-2229-8-58

Brunoud, G., Wells, D. M., Oliva, M., Larrieu, A., Mirabet, V., Burrow, A. H., et al. (2012). A novel sensor to map auxin response and distribution at high spatio-temporal resolution. Nature 482, 103-106. doi: 10.1038/nature1 0791

Buono, R. A., Hudecek, R., and Nowack, M. K. (2019). Plant proteases during developmental programmed cell death. J. Exp. Bot. 70, 2097-2112. doi: 10.1093/ jxb/erz072

Carimi, F., Zottini, M., Costa, A., Cattelan, I., Michele, R. D., Terzi, M., et al. (2005). NO signalling in cytokinin-induced programmed cell death. Plant Cell Environ. 28, 1171-1178. doi: 10.1111/j.1365-3040.2005.01355.x

Chen, G. H., Sun, J. Y., Liu, M., Jie, L., and Yang, W. C. (2014). SPOROCYTELESS is a novel embryophyte-specific transcription repressor that interacts with TPL and TCP proteins in Arabidopsis. J. Genet. Genomics 41, 617-625. doi: 10.1016/ j.jgg.2014.08.009

Chen, H. M., Yu, P., Zeng, J., Qi, D., Yin, S. Y., Liu, C., et al. (2012). The $\mathrm{Ca}^{2+}$ dependent DNases are involved in secondary xylem development in Eucommia ulmoides. J. Integr. Plant Biol. 54, 456-470. doi: 10.1111/j.1744-7909.2012. 01134.x

Cubría-Radío, M., and Nowack, M. K. (2019). Transcriptional networks orchestrating programmed cell death during plant development. Curr. Top. Dev. Biol. 131, 161-184. doi: 10.1016/bs.ctdb.2018.10.006

Daneva, A., Gao, Z., Durme, M. V., and Nowack, M. K. (2016). Functions and regulation of programmed cell death in plant development. Annu. Rev. Cell Dev. Bi. 32, 441-468.

Demesa-Arévalo, E., and Vielle-Calzada, J. P. (2013). The classical arabinogalactan protein AGP18 mediates megaspore selection in Arabidopsis. Plant Cell 25, 1274-1287. doi: 10.1105/tpc.112.106237

Denay, G., Cre, Ff, A., Moussu, S., Wagnon, P., Thévenin, J., et al. (2014). Endosperm breakdown in Arabidopsis requires heterodimers of the basic helix-loop-helix proteins ZHOUPI and INDUCER OF CBP EXPRESSION 1. Development 141, 1222-1227. doi: 10.1242/dev.103531

Eriksson, M. E., Israelsson, M., Olsson, O., Moritz, T. (2000). Increased gibberellin biosynthesis in transgenic trees promotes growth, biomass production and xylem fiber length. Nat. Biotechnol. 18, 784-788. doi: 10.1038/7 7355

Escamez, S., and Tuominen, H. (2014). Programmes of cell death and autolysis in tracheary elements: when a suicidal cell arranges its own corpse removal. J. Exp. Bot. 65, 1313-1321. doi: 10.1093/jxb/eru057

Fendrych, M., Hautegem, T. V., Durme, M. V., Olvera-Carrillo, Y., Huysmans, M., Karimi, M., et al. (2014). Programmed cell death controlled by ANAC033/SOMBRERO determines root cap organ size in Arabidopsis. Curr. Biol. 24, 931-940. doi: 10.1016/j.cub.2014.03.025

Fu, Z., Yu, J., Cheng, X., Zong, X., Xu, J., Chen, M., et al. (2014). The Rice basic Helix-Loop-Helix transcription factor TDR INTERACTING PROTEIN2 ss a central switch in early anther development. Plant Cell 26, 1512-1524. doi: $10.1105 /$ tpc.114.123745

Gadjev, I., Vanderauwera, S., Gechev, T. S., Laloi, C., Minkov, I. N., Shulaev, V., et al. (2006). Transcriptomic footprints disclose specificity of reactive oxygen species signaling in Arabidopsis. Plant Physiol. 141, 436-445. doi: 10.1104/pp. 106.078717

Gechev, T. S., Breusegem, F. V., Stone, J. M., Denev, I., and Laloi, C. (2006). Reactive oxygen species as signals that modulate plant stress responses and programmed cell death. BioEssays 28, 1091-1101. doi: 10.1002/bies.20493

Gechev, T. S., and Hille, J. (2005). Hydrogen peroxide as a signal controlling plant programmed cell death. J. Cell Biol. 168, 17-20. doi: 10.1083/jcb.20040 9170

Gómez, J. F., Talle, B., and Wilson, Z. A. (2015). Anther and pollen development: a conserved developmental pathway. J. Integr. Plant Biol. 57, 876-891. doi: 10.1111/jipb.12425

Graaff, E. V. D., Schwacke, R., Schneider, A., Desimone, M., Flügge, U., and Kunze, R. (2006). Transcription analysis of Arabidopsis membrane transporters and hormone pathways during developmental and induced leaf senescence. Plant Physiol. 141, 776-792. doi: 10.1104/pp.106.079293
Groover, A., and Jones, A. M. (1999). Tracheary element differentiation uses a novel mechanism coordinating programmed cell death and secondary cell wall synthesis. Plant Physiol. 119, 375-384. doi: 10.1104/pp.119.2.375

Gunawardena, A. H. L. A. N. (2008). Programmed cell death and tissue remodelling in plants. J. Exp. Bot. 59, 445-451. doi: 10.1093/jxb/erm189

Han, S., Fang, L., Ren, X., Wang, W., and Jiang, J. (2014). MPK6 controls $\mathrm{H}_{2} \mathrm{O}_{2}$ induced root elongation by mediating $\mathrm{Ca}^{2+}$ influx across the plasma membrane of root cells in Arabidopsis seedlings. New Phytol. 205, 695-706. doi: 10.1111/ nph. 12990

He, Y., Fukushige, H., and Gan, H. S. (2002). Evidence supporting a role of jasmonic acid in Arabidopsis leaf senescence. Plant Physiol. 128, 876-884. doi: 10.1104/pp.010843

Hirano, K., Aya, K., Hobo, T., Sakakibara, H., Kojima, M., Shim, R. A., et al. (2008). Comprehensive transcriptome analysis of phytohormone biosynthesis and signaling genes in microspore/pollen and tapetum of rice. Plant Cell Physiol. 49, 1429-1450. doi: 10.1093/pcp/pcn123

Hu, L., Liang, W., Yin, C., Cui, X., Zong, J., Wang, X., et al. (2011). Rice MADS3 regulates ROS homeostasis during late anther development. Plant Cell 23, 515-533. doi: 10.1105/tpc.110.074369

Huysmans, M., Buono, R. A., Skorzinski, N., Radio, M. C., Winter, F. D., Parizot, B., et al. (2018). NAC transcription factors ANAC087 and ANAC046 control distinct aspects of programmed cell death in the Arabidopsis columella and lateral root cap. Plant Cell 30, 2197-2213. doi: 10.1105/tpc.18. 00293

Huysmans, M., Saul, L. A., Coll, N. S., and Nowack, M. K. (2017). Dying two deaths-programmed cell death regulation in development and disease. Curr. Opin. Plant Biol. 35, 37-44. doi: 10.1016/j.pbi.2016.11.005

Iakimova, E. T., and Woltering, E. J. (2015). Nitric oxide prevents wound-induced browning and delays senescence through inhibition of hydrogen peroxide accumulation in fresh-cut lettuce. Innov. Food Sci. Emerg. 30, 157-169. doi: 10.1016/j.ifset.2015.06.001

Kaminaka, H., Näke, C., Epple, P., Dittgen, J., Schütze, K., Chaban, C., et al. (2006). bZIPI10-LSD1 antagonism modulates basal defense and cell death in Arabidopsis following infection. EMBO J. 25, 4400-4411. doi: 10.1038/sj.emboj. 7601312

Kapoor, D., Sharma, R., Handa, N., Kaur, H., Rattan, A., Yadav, P., et al. (2015). Redox homeostasis in plants under abiotic stress: role of electron carriers, energy metabolism mediators and proteinaceous thiols. Front. Env. Sci. 3:13. doi: $10.3389 /$ fenvs.2015.00013

Kessler, S. A., and Grossniklaus, U. (2011). She's the boss: signaling in pollen tube reception. Curr. Opin. Plant Biol. 14, 622-627. doi: 10.1016/j.pbi.2011. 07.012

Kim, H. J., Ryu, H., Hong, S. H., Woo, H. R., Lim, P. O., Lee, I. C., et al. (2006). Cytokinin-mediated control of leaf longevity by AHK3 through phosphorylation of ARR2 in Arabidopsis. Proc. Natl. Acad. Sci. U. S. A. 103, 814-819. doi: 10.1073/pnas.0505150103

Kirik, V., Bouyer, D., Schbinger, U., Bechtold, N., Herzog, M., Bonneville, J.M., et al. (2001). CPR5 is involved in cell proliferation and cell death control and encodes a novel transmembrane protein. Curr. Biol. 11, 1891-1895. doi: 10.1016/s0960-9822(01)00590-5

Ko, S. S., Li, M. J., Ku, S. B., Ho, Y. C., Lin, Y. J., Chuang, M. H., et al. (2014). The bHLH142 transcription factor coordinates with TDR1 to modulate the expression of EAT1 and regulate pollen development in rice. Plant Cell 26, 2486-2504. doi: 10.1105/tpc.114.126292

Kong, D., Ju, C., Parihar, A., Kim, S., Cho, D., and Kwak, J. M. (2015). Arabidopsis glutamate receptor homolog3.5 modulates cytosolic $\mathrm{Ca}^{2+}$ level to counteract effect of abscisic acid in seed germination. Plant Physiol. 167, 1630-1642. doi: 10.1104/pp.114.251298

Kumpf, R. P., and Nowack, M. K. (2015). The root cap: a short story of life and death. J. Exp. Bot. 19, 5651-62. doi: 10.1093/jxb/erv295

Kunikowska, A., Byczkowska, A., and Kazmierczak, A. (2013). Kinetin induces cell death in root cortex cells of Vicia faba ssp. minor seedlings. Protoplasma 250, 851-861. doi: 10.1007/s00709-012-0466-7

Lee, K. P., Kim, C., Landgraf, F., and Apel, K. (2007). EXECUTER1- and EXECUTER2-dependent transfer of stress-related signals from the plastid to the nucleus of Arabidopsis thaliana. Proc. Natl. Acad. Sci. U. S. A. 104, 10270-10275. doi: $10.1073 /$ pnas.0702061104 
Li, Z., Peng, J., Wen, X., and Guo, H. (2013). Ethylene-insensitive 3 is a senescenceassociated gene that accelerates age-dependent leaf senescence by directly repressing miR164 transcription in Arabidopsis. Plant Cell 25, 3311-3328. doi: 10.1105/tpc.113.113340

Liang, Y., Tan, Z. M., Zhu, L., Niu, Q. K., Zhou, J. J., Li, M., et al. (2013). MYB97, MYB101 and MYB120 function as male factors that control pollen tube-synergid interaction in Arabidopsis thaliana fertilization. PLoS Genet. 9:e1003933. doi: 10.1371/journal.pgen.1003933

Liu, H., Hao, N., Jia, Y., Liu, X., Ni, X., Wang, M., et al. (2019). The ethylene receptor regulates Typha angustifolia leaf aerenchyma morphogenesis and cell fate. Planta 250, 381-390. doi: 10.1007/s00425-019-03177-4

Liu, Y., Ren, D., Pike, S., Pallardy, S., Gassmann, W., and Zhang, S. (2007). Chloroplast-generated reactive oxygen species are involved in hypersensitive response-like cell death mediated by a mitogen-activated protein kinase cascade. Plant J. 51, 941-954. doi: 10.1111/j.1365-313x.2007.03 191.x

Lombardi, L., Ceccarelli, N., Picciarelli, P., Lorenzi, R. (2010). Nitric oxide and hydrogen peroxide involvement during programmed cell death of Sechium edule nucellus. Physiol. Plant. 140, 89-102. doi: 10.1111/j.1399-3054.2010. 01381.x

Matallana-Ramirez, L. P., Rauf, M., Farage-Barhom, S., Dortay, H., Xue, G. P., Dröge-Laser, W., et al. (2013). NAC transcription factor ORE1 and senescence-induced BIFUNCTIONAL NUCLEASE1 (BFN1) constitute a regulatory cascade in Arabidopsis. Mol. Plant 6, 1438-1452. doi: 10.1093/mp/sst 012

Milhinhos, A., and Miguel, C. M. (2013). Hormone interactions in xylem development: a matter of signals. Plant Cell Rep. 32, 867-883. doi: 10.1007/ s00299-013-1420-7

Mur, L. A. J., Mandon, J., Persijn, S., Cristescu, S. M., Moshkov, I. E., Novikova, G. V., et al. (2012). Nitric oxide in plants: an assessment of the current state of knowledge. AoB Plants 5:pls052. doi: 10.1093/aobpla/pls052

Ngo, Q. A., Vogler, H., Lituiev, D. S., Nestorova, A., and Grossniklaus, U. (2014). A calcium dialog mediated by the FERONIA signal transduction pathway controls plant sperm delivery. Dev. Cell 29, 491-500. doi: 10.1016/j.devcel.2014. 04.008

Niu, L., and Liao, W. (2016). Hydrogen peroxide signaling in plant development and abiotic responses: crosstalk with nitric oxide and calcium. Front. Plant Sci. 7:230. doi: 10.3389/fpls.2016.00230

Olvera-Carrillo, Y., Bel, M. V., Hautegem, T. V., Fendrych, M., Huysmans, M., Simaskova, M., et al. (2015). A conserved core of programmed cell death indicator genes discriminates developmentally and environmentally induced programmed cell death in plants. Plant Physiol. 169, 2683-2699.

Papini, A., Tani, G., Falco, P. D., and Brighigna, L. (2010). The ultrastructure of the development of Tillandsia (Bromeliaceae) trichome. Flora 205, 94-100. doi: 10.1016/j.flora.2009.02.001

Petrov, V., Hille, J., Mueller-Roeber, B., and Gechev, T. S. (2015). ROS-mediated abiotic stress-induced programmed cell death in plants. Front. Plant Sci. 6:69. doi: 10.3389/fpls.2015.00069

Phan, H. A., Iacuone, S., Li, S. F., and Parish, R. W. (2011). The MYB80 transcription factor is required for pollen development and the regulation of tapetal programmed cell death in Arabidopsis thaliana. Plant Cell 23, 22092224. doi: 10.1105/tpc.110.082651

Radchuk, V., Weier, D., Radchuk, R., Weschke, W., and Weber, H. (2011). Development of maternal seed tissue in barley is mediated by regulated cell expansion and cell disintegration and coordinated with endosperm growth. J. Exp. Bot. 62, 1217-1227. doi: 10.1093/jxb/erq348

Radojičić, A., Li, X., and Zhang, Y. (2018). Salicylic acid: a double-edged sword for programed cell death in plants. Front. Plant Sci. 9:1133. doi: 10.3389/fpls.2018. 01133

Rantong, G., Evans, R., and Gunawardena, A. H. L. A. N. (2015). Lace plant ethylene receptors, AmERS1a and AmERS1c, regulate ethylene-induced programmed cell death during leaf morphogenesis. Plant Mol. Biol. 89, 215227. doi: 10.1007/s11103-015-0356-4

Rantong, G., and Gunawardena, A. H. L. A. N. (2018). Vacuolar processing enzymes, AmVPE1 and AmVPE2, as potential executors of ethylene regulated programmed cell death in the lace plant (Aponogeton madagascariensis). Botany 96, 235-247. doi: 10.1139/cjb-2017-0184
Rauf, M., Arif, M., Dortay, H., Matallana-Ramírez, L. P., Waters, M. T., Nam, H. G., et al. (2013). ORE1 balances leaf senescence against maintenance by antagonizing G2-like-mediated transcription. EMBO Rep. 14, 382-388. doi: 10.1038/embor.2013.24

Ravichandran, S. J., Linh, N. M., and Scarpella, E. (2020). The canalization hypothesis-challenges and alternatives. New Phytol. 227, 1051-1059. doi: 10. $1111 /$ nph.16605

Sheldrake, A. R. (2021). The production of auxin by dying cells. J. Exp. Bot. 72, 2288-2300. doi: 10.1093/jxb/erab009

Steffens, B., and Sauter, M. (2005). Epidermal cell death in rice is regulated by ethylene, gibberellin, and abscisic acid. Plant Physiol. 139, 713-721. doi: 10. 1104/pp.105.064469

Uslu, V. V., and Grossmann, G. (2016). The biosensor toolbox for plant developmental biology. Curr. Opin. Plant Biol. 29, 138-147. doi: 10.1016/j.pbi. 2015.12.001

Uzair, M., Xu, D., Schreiber, L., Shi, J., Liang, W., Jung, K., et al. (2020). PERSISTENT TAPETAL CELL 2 is required for normal tapetal programmed cell death and pollen wall patterning. Plant Physiol. 182, 962-976. doi: 10.1104/ pp. 19.00688

Vanneste, S., and Friml, J. (2009). Auxin: a trigger for change in plant development. Cell 136, 1005-1016. doi: 10.1016/j.cell.2009.03.001

Vescovi, M., Riefler, M., Gessuti, M., Novak, O., Schmulling, T., and Schiavo, L. F. (2012). Programmed cell death induced by high levels of cytokinin in Arabidopsis cultured cells is mediated by the cytokinin receptor CRE1/AHK4. J. Exp. Bot. 63, 2825-2832. doi: 10.1093/jxb/ers008

Wang, D. H., Li, F., Duan, Q. H., Han, T., Xu, Z. H., and Bai, S. N. (2010). Ethylene perception is involved in female cucumber flower development. Plant J. 61, 862-872. doi: 10.1111/j.1365-313x.2009.04114.x

Wang, Y., Liu, R., Chen, L., Liang, Y., Wu, X., Li, B., et al. (2009). Nicotiana tabacum TTG1 contributes to ParAl-induced signalling and cell death in leaf trichomes. J. Cell Sci. 122, 2673-2685. doi: 10.1242/jcs.049023

Wang, Y., Ye, H., Bai, J., and Ren, F. (2021). The regulatory framework of developmentally programmed cell death in floral organs: a review. Plant Physiol. Biochem. 158, 103-112. doi: 10.1016/j.plaphy.2020.11.052

Wilkins, K. A., Bancroft, J., Bosch, M., Ings, J., Smirnoff, N., and Franklintong, V. E. (2011). ROS and NO mediate actin reorganization and programmed cell death in the self-incompatibility response of Papaver. Plant Physiol. 156, 404-416. doi: 10.1104/pp.110.167510

Wilkins, K. A., Bosch, M., Haque, T., Teng, N., Poulter, N. S., and Franklin-Tong, V. E. (2015). Self-incompatibility-induced programmed cell death in Papaver pollen involves dramatic acidification of the incompatible pollen tube cytosol. Plant Physiol. 167, 766-779. doi: 10.1104/pp.114.252742

Woo, H. R., Kim, H. J., Lim, P. O., and Nam, H. G. (2019). Leaf senescence: systems and dynamics aspects. Annu. Rev. Plant Biol. 70, 15.11-15.30.

Xie, H. T., Wan, Z. Y., Li, S., and Zhang, Y. (2014). Spatiotemporal production of reactive oxygen species by NADPH oxidase is critical for tapetal programmed cell death and pollen development in Arabidopsis. Plant Cell 26, 2007-2023. doi: 10.1105/tpc.114.125427

Xie, X., Zhang, Z., Zhao, Z., Xie, Y., Li, H., Ma, X., et al. (2020). The mitochondrial aldehyde dehydrogenase OsALDH2b negatively regulates tapetum degeneration in rice. J. Exp. Bot. 71, 2551-2560. doi: 10.1093/jxb/ eraa045

Xuan, W., Band, L. R., Kumpf, R. P., Damme, D. V., Parizot, B., Rop, G. D., et al. (2016). Cyclic programmed cell death stimulates hormone signaling and root development in Arabidopsis. Science 351, 384-387. doi: 10.1126/science. $\operatorname{aad} 2776$

Yin, L. L., and Xue, H. W. (2012). The MADS29 transcription factor regulates the degradation of the nucellus and the nucellar projection during rice seed development. Plant Cell 24, 1049-1065. doi: 10.1105/tpc.111.094854

Zhang, D., Di, L., Lv, X., Wang, Y., Xun, Z., Liu, Z., et al. (2014). The cysteine protease CEP1, a key executor involved in tapetal programmed cell death, regulates pollen development in Arabidopsis. Plant Cell 26, 2939-2961. doi: $10.1105 /$ tpc. 114.127282

Zhang, J., Xie, M., Tuskan, G. A., Muchero, W., and Chen, J. G. (2018a). Recent advances in the transcriptional regulation of secondary cell wall biosynthesis in the woody plants. Front. Plant Sci. 9:1535. doi: 10.3389/fpls.2018.01535

Zhang, J., Yang, Y., Zheng, K., Xie, M., Feng, K., Jawdy, S. S., et al. (2018b). Genomewide association studies and expression-based quantitative trait loci analyses 
reveal roles of HCT2 in caffeoylquinic acid biosynthesis and its regulation by defense-responsive transcription factors in Populus. New Phytol. 220, 502-516. doi: $10.1111 /$ nph. 15297

Zhong, R., Lee, C., and Ye, Z. H. (2010). Global analysis of direct targets of secondary wall NAC master switches in Arabidopsis. Mol. Plant 3, 1087-1103. doi: $10.1093 / \mathrm{mp} / \mathrm{ssq} 062$

Zhong, R., Richardson, E. A., and Ye, Z. H. (2007). The MYB46 transcription factor is a direct target of SND1 and regulates secondary wall biosynthesis in Arabidopsis. Plant Cell 19, 2776-2792. doi: 10.1105/tpc.107.053678

Conflict of Interest: The authors declare that the research was conducted in the absence of any commercial or financial relationships that could be construed as a potential conflict of interest.
Publisher's Note: All claims expressed in this article are solely those of the authors and do not necessarily represent those of their affiliated organizations, or those of the publisher, the editors and the reviewers. Any product that may be evaluated in this article, or claim that may be made by its manufacturer, is not guaranteed or endorsed by the publisher.

Copyright (c) 2021 Jiang, Wang, Leng, Wang, Liu, Lu, Lu and Zhang. This is an open-access article distributed under the terms of the Creative Commons Attribution License (CC BY). The use, distribution or reproduction in other forums is permitted, provided the original author(s) and the copyright owner(s) are credited and that the original publication in this journal is cited, in accordance with accepted academic practice. No use, distribution or reproduction is permitted which does not comply with these terms. 